\title{
Development of Deterministic Thinking Scale Based on Iranian Culture
}

\author{
Jalal Younesi, Akram Alsadat Mirafzal \\ University of Social Welfare and Rehabilitation Sciences, Tehran, Iran \\ Email: jyounesi@uswr.ac.ir
}

Received August $5^{\text {th }}, 2013$; revised September $6^{\text {th }}, 2013$; accepted October $7^{\text {th }}, 2013$

\begin{abstract}
Copyright (C) 2013 Jalal Younesi, Akram Alsadat Mirafzal. This is an open access article distributed under the Creative Commons Attribution License, which permits unrestricted use, distribution, and reproduction in any medium, provided the original work is properly cited.
\end{abstract}

\begin{abstract}
One of major cognitive distortions is deterministic thinking. This type of thinking ignores any possibility or probability in conclusion about the events. Any consequence of event may be thought such as: $2 \times 2=$ 4. Equality is a dominant factor among all conclusions of this kind of distortion. In Islamic perspective, the distortion is seen as a destructive factor for ruining balance of fear and hope, which is to be an important sign of people's faith. The distortion emerges in cognitive rigidity in the mind which may be mother of all distortions. Cognitive rigidity is a main reason for depression and other psychosocial maladjustment. The scale with 36 items was developed in first phase of this study. Its validity and reliability were measured among men and women. It had reasonable and significant correlation with Beck Depression Inventory $(p \leq .05)$ and also showed reasonable internal reliability $(\alpha=.8218)$. Through factor analysis, five factors appeared in this type of thinking to be related to General deterministic thinking, Deterministic thinking in interaction with people, Absolute view in thinking, Deterministic thinking in prediction of future and Deterministic thinking in negative events.
\end{abstract}

Keywords: Deterministic Thinking; Cognitive Distortions; Balance of Fear and Hope; Islamic Culture; Cognition

\section{Introduction}

Plato' idealism insists that our perceptions determine the reality that we experience.

This reminds us the "Plato's Cave", which is reality to be defined as the figures that one sees outside the cave (Leahy, 1996). The approach that "reality is determined by cognition" has a long history in Western philosophy. For example, Kant's $(1782 / 1988)$ philosophy of mind was based on the view that reality is never directly knowable, but rather is "known" through "categories of thinking" (Leahy, 1987). According to Kant, all knowledge was based on the "categories", which today we would call schemas, and the reality was never directly knowable but only to know through the schemas. This is not a notion which merely to be stated in western philosophy because there are same points from religious perspective. For instance, Prophet Mohammad (S) wishes in his praying "may Allah show me the reality as it is" (Younesi, 2005; Younesi, Asgary, \& Bahrami, 2009). Human being is sometimes described remoteness from the reality in Quran as "being arrogant when to see himself needless" (Quran, 95; 6,7) while "only the god is needless" (Quran, 112; 2). In point of psychopathology, how people think about themselves or the world around them seems to make a major difference to their level of vulnerability to stress, anxiety and depression. This is more than simply being optimistic or pessimistic - there are certain thinking methods which help people to cope better than others (Warner, 2000). It is reasonable to see cognitive therapy as the attempt to get the patient to unchain himself from inappropriate cognitions and to see the reality as it is (Beck, 2008; Beck et al., 1979; Leahy, 1996). These wrong cognitions are named cognitive distortions. They are inaccurate thoughts or ideas which to maintain negative thinking and help to maintain negative emotions. The theory of cognitive distortions was first proposed by Burns (1989). Eliminating these distortions and negative thought is said to improve mood and discourage maladies such as depression and chronic anxiety (Beck, 1983). There are many cognitive distortions which have a major role in forming depression and anxiety (Beck et al., 1979; Beck et al., 1983; Burns, 1989; Teasdale, 1993; Teasdale \& Bernard, 1993; Clarck \& Fairburn, 1997; Smit, Rosenfield, \& Mcdonald, 2006; Del Missier, Ferrante, \& Costantini, 2007). Some of these distortions include (Sommers-Flanagan 2004; Leahy, 1996): Arbitrary Inference, Selective Abstraction, Personalization, Dichotomous Thinking, Labeling and mislabeling, Magnification and minimization, overgeneralization, etc. One of major cognitive distortions is deterministic thinking (Younesi \& Mirafzal, 2007). This type of thinking ignores any possibility or probability in conclusion about the events and to be able to create many cognitive distortions because any distortion leads to conclusion; and distortion of deterministic thinking to rule out any probability or possibility in concluding (Younesi, Younesi, \& Asgary, 2008).

Any consequences of events may be thought such as: $2 \times 2=$ 4. Equality is a dominant factor among all conclusions of this kind of thought, i.e.: divorcing from wife = misery. The distortion emerges in cognitive rigidity in the mind and may be mother of all distortions (Younesi, 2005). Cognitive rigidity is a 
main reason for depression and other psychosocial maladjustment (Beck, 1980; Weissar \& Beck, 1992).

In religious perspective, which is sometimes essential to be considered in cognitive therapy for some people (SommersFlanagan, 2004), this distortion is seen as destructive factor for ruining balance of fear and hope (Younesi, 2005; Younesi \& Mirafzal, 2007) because any exception for consequences of bad or good events is to be ruled out by deterministic thinking.

There is an strong comment from most important religious leaders of Islam for keeping the balance of fear and hope as sign of faith and mental health (for example: Imam Ali (S), ground sons of great prophet Mohammad $<\mathrm{S}>$ (Al tamimi Al madi \& Abdolvahed, 1979; Faizol Al Islam \& Alinaghi, 1973; Koleini \& Seghet Al Islam, 1980). In prediction of consequences of favourite or undesirable events, any deterministic thinking about the events has been rejected in Holy Quran: "sometimes undesirable event may bring you luck and sometimes desired one to bring you un luck" (Quran, 2, 216). So being too disappointed or too hopeful in relation with the events, either positive or negative is not accepted in this perspective. Since prediction of any event is not certainly possible in this view, even prediction of "god's will" is not promising in Shiite perspective (Arafeh praying, Imam Hossein $<\mathrm{S}>$, Ghommi, 1989). This view is called "bada" in Shiite belief which means everything can be initiated from beginning. There is a sentence in Islamic culture which is widely used by people in western and eastern countries when to confront with events, that is: "Insha Allah" means "If the God Wants". The sentence is in opposite direction of deterministic thinking because any consequence of events to come back to will of God which god only to know (Younesi, 2005). Similarly in scientific approach, accepting or rejecting hypothesis by $\mathrm{P}$ value of zero is avoided in spite of possessing firm experimental reasons. The main reason for the approach is that some scientists believe in no absolute reality which can be imperfect because our perception of events and realities to be not from beginning or final state.

Creatures and events are identified partially from not initiating or ending (Jaafari, 1982): "You don't aware of what to be gradually creating in world of creature." (Quran, 16, 8). "What are in the earth or sky to request from god and every day he to be in position of creating" (Quran, 55, 29). In this philosophy, creation is not finished and to be expected new creation so in this ongoing job to be not possible prediction of life's events surely.

Development of an instrument which can be able to measure the rate of deterministic thinking based on religious perspective and Islamic culture to be the aim of the study. Measuring of deterministic thinking is milestone for studying the nature of depression and anxiety or other maladjustment (Younesi, 2005).

\section{Material and Method}

Based on characteristics of balance in fear and hope and comments of religious leaders (above references) and characteristics of cognitive rigidity (Beck, 1980; Weissar \& Beck, 1992), items of deterministic thinking scale were developed. First of all 52 items were made which to refer to prediction of the events and behaviors. The items include: Behaviors of people in future i.e.: "Behaviors and reactions of people will be predicted certainly".

Positive and negative events in future i.e.: "in spite of solid reasons, nobody can predict bad and good events of life defi- nitely".

- Forgiveness such as: "It is sensible to forgive bad behaviors of individuals when we do not believe the behaviors to be repeated certainly".

- Behaviors of couples such as: "if somebody has behaved well frequently with his/her partner, he/she will do certainly as the same as before".

- Will of God such as: "Nothing is certain in this world, even God's will; because it is possible to change the God's will by praying".

- Future of human beings i.e.: "If human beings have more knowledge, they will able to predict events of life absolutely positive".

- Social relationship: "Certain conclusion from reactions and behavior of people is one of major pathology in social relationship".

The content validity of the Scale was approved by five experts including: Clinical Psychologist, Psychometric, expert in Islamic Knowledge, counselor and psychologist with profession in Islamic culture.

The instrument is responded by four options: I agree totally, I agree partially, I disagree totally, I disagree partially. Beck' depression Inventory (BDI) [Beck 1968] is utilized for measureing the congruent validity. 97 men and women were examined by the scale and BDI in a pilot study who were collected randomly in Tehran. Using factor analysis, RISREL and other statistical analysis, reliability and validity of the scale were measured and necessary modifications to be implemented. Moreover 600 men and women randomly involved in a main study who to be questioned by developed deterministic thinking scale.

\section{Results}

Table 1 demonstrates demographic data of subjects in pilot study:

Table 2 shows the results of Pearson correlation between Deterministic thinking scale (DTS) and BDI:

After measuring reliability, 14 items were omitted from the scale in pilot study and reliability coefficient 38 items of the scale was .8218 . Two items of DTS were removed by RISREL analysis.

DTS was computed by Principal Component Analysis.

The results of Component analysis shown in Table 3:

Five factors emerged in the scale with 36 items which were named based on contents of the items:

1) General deterministic thinking (9 items)

2) Deterministic thinking in interaction with people (8 items)

3) Absolute view in thinking (7 items)

4) Deterministic thinking in prediction of future (6 items)

5) Deterministic thinking in negative events (6 items)

In additional study 50 subject including 25 men and same number women answered DTS by one week interval in Tehran. The Reliability over time of the scale was $(\mathrm{r}=.87 ; p \leq .5)$.

DTS was reanalyzed by factor analysis in the main study which 300 couples to answer the scale. The results showed

Table 1.

The demographic data of subjects in pilot study.

\begin{tabular}{ccccc}
\hline Female & Male & Married & Single & Age of subjects (mean) \\
\hline 50 & 47 & 50 & 47 & $31.6($ SD 10.67) \\
\hline
\end{tabular}


Table 2.

The results of Pearson correlation between DTS and BDI.

\begin{tabular}{ccc}
\hline Number of subjects & DTS & BDI \\
\hline 97 & 1 & $.33^{*}$
\end{tabular}

Note: ${ }^{*}(p \leq .01)$-two tailed.

Table 3.

The results of component analysis in the study.

\begin{tabular}{cccc}
\hline \multicolumn{4}{c}{ Initial Eigen values } \\
\hline Components & Total & \% of V & Cum\% \\
\hline 1 & 5.596 & 14.725 & 14.725 \\
2 & 2.990 & 7.867 & 22.593 \\
3 & 2.378 & 6.257 & 28.849 \\
4 & 2.061 & 5.423 & 34.272 \\
5 & 1.745 & 4.592 & 38.865 \\
\hline
\end{tabular}

repeatedly five factors to exist in DTS and to possess significant factorial loading. In Table 4, statistical characteristics of discovery and confirmatory factor analysis of DTS were shown.

\section{Discussion}

The results show that DTS to enjoy good reliability and validity. The congruent validity of scale which emerged with Beck Depression Inventory to show reasonable correlation (./33, $p \leq .01)$. This finding has harmony with views of many psychologists and cognitive therapists who to insist on role of cognitive distortions as main factor of developing depression (Gertner, 2003; Baron, 2000; Rottenstreich \& Hsee, 2001; Leahy, 1996; Sommers-Flanagan \& Sommers-Flanagan, 2004; Beck, 2008; Beck, Epstein, \& Harrison, 1983; Teasdale, 1993). Moreover it was predictable to see such correlation between two instruments because of similarities between deterministic thinking and cognitive rigidity (Younesi, 2005). In other hand, it is clear that Cognitive rigidity to be a main reason for depression and other psychosocial disorders (Beck, 1975; Weissar \& Beck, 1992). In another study, Younesi, Asgary, \& Bahrami (2008) found significant negative correlation between Enrich marital satisfaction inventory and DTS. It seems that deterministic thinking as a cognitive distortion to be devastating factor either in depression or marital relationship of couples.

It is apparent that cognitive distortions to have eminent role in decreasing of marital satisfaction (Klaff, 2007; Shapiro, 2007; Gottman, Coan, Carrère, \& Swanson, 1998; Fincham, Harold, \& Gano-Philips, 2000)

Momeni (2008) measured sensitivity of DTS among happy and unhappy couples who to request the family court for divorce. He found significant and reasonable sensitivity of DTS for distinguishing these two groups of couples.

Results of factor analysis appeared five factors which to confirm either main or pilot study. First factor as a general one counts 14.725 of variance and to include 9 items. These items measure the whole view of subjects towards life in angel of determinism, i.e.: "if humans are not able to conclude certainly about life events, the anarchy and chaos will rule on the life". Second factor which counts 7.86 of variance and to refers to
Deterministic thinking in interaction with people to contain 8 items, i.e.: "It is always possible to have precise prediction from actions and behaviors of people". Third factor which is related to absolute view in thinking consisting of 7 items and to count 6.26 of variance, i.e.: "if a person behaved badly with somebody, he/she will certainly repeat it again." The fourth factor is named Deterministic thinking in prediction of future to comprise 6 items and counting 5.42 of variance, i.e.: "It is possible to predict behaviors and reactions of people definitely." Finally, fifth factor is named Deterministic thinking in negative events and to take account 6 items, counting 4.59 of variance, i.e.: "if some bad events happen in the life, it is equal of big misfortune".

It seems that DTS to be able to measure different angles of deterministic thinking. This characteristic of the scale corresponds with variety roles of cognitive distortions which to have negative impact psychosocial life of people (Baron, 2000; Rottenstreich \& Hsee, 2001; Warner, 2000; Smit, Rosenfield, \& Mcdonald, 2006).

There are some similarities between items of factors involved in DTS and some cognitive biases which to be found by some authors. For instance, cognitive bias of focusing effect is similar with items of factor $5 \& 3$. The focusing effect is a cognitive bias that occurs when people place too much importance on one aspect of an event, causing an error in accurately predicting the utility of a future outcome. People focus on notable differences, excluding those that are less eye-catching, when making predictions about happiness or handiness (Del Missier, Ferrante, \& Costantini, 2007; Schkade \& Kahneman, 1998). Also some authors suggested the neglect of probability bias, a type of cognitive bias, is the tendency to completely disregard probability when making a decision under uncertainty and is one simple way in which people regularly violate the normative rules for decision making Baron, 2000; Rottenstreich \& Hsee, 2001). This bias is comparable with some items of DTS in factors $2 \&$ 4 which to ignore any probability in conclusions.

One of the unique features of DTS which makes it different from other scales of measuring cognitive distortions, to consider principal of balancing between fear and hope (Al tamimi Al madi \& Abdolvahed, 1979; Faizol Al Islam \& Alinaghi, 1973; Koleini \& Seghet Al Islam, 1980; Younesi, 2005; Younesi \& Mirafzal, 2007). So, there was an attempt to measure deterministic thinking either positive or negative events in development of the items of the scale.

The author and his colleagues were studied relation between deterministic thinking (DT) and mental health, communicational skills and marital satisfaction. The results showed that to exist the negative correlation between DTQ and communicational skills among couples (Maghsoudzade, 2010); reverse correlation between DTQ and forgiveness scale (Borooghani, 2010); negative correlation between DTQ and Enrich Marital Satisfaction Scale (Younesi \& Bahrami, 2009), negative correlation between DTQ and hope scale (Rah Anjam, 2010) and positive correlation between DTQ and marital conflicts scale (Momeni, 2008). These researches indicate that DT plays a destructive role the interactions of people in family and society circumstances, addressing DT in cognitive therapy can help clients to reduce their anxiety and depression (Younesi, Younesi, \& Asgary, 2008).

It is suggested that the role of DT in producing social phobia and hopelessness and helplessness as milestones of depression be investigated. Moreover it is suggested to investigate between 
Table 4.

Statistical characteristics of discovery and confirmatory factor analysis of DT.

\begin{tabular}{ccccccc}
\hline & \multicolumn{2}{c}{ Discovery } & \multicolumn{3}{c}{ Confirmatory } \\
\hline Factors & Special value & Percent of value & Reliability coefficient & Standard coefficient & T & $\mathbf{R}^{2}$ \\
\hline First & $4 / 68$ & $13 / 01$ & $0 / 71$ & $0 / 37$ & $4 / 68$ & $0 / 14$ \\
Second & $3 / 42$ & $9 / 51$ & $0 / 61$ & $-0 / 24$ & $4 / 68$ & $0 / 10$ \\
Third & $1 / 79$ & $4 / 98$ & $0 / 70$ & $-0 / 52$ & $4 / 68$ & $0 / 38$ \\
Fourth & $1 / 55$ & $4 / 31$ & $0 / 59$ & $0 / 52$ & $4 / 68$ & $0 / 38$ \\
Fifth & $1 / 49$ & $4 / 16$ & $0 / 64$ & $0 / 48$ & $4 / 68$ & $0 / 23$ \\
\hline
\end{tabular}

Note: $\mathrm{X}^{2}=2 / 51 ; p=0 / 28 ; \mathrm{KMO}=0 / 793 ;$ Bartlett test $=3867 / 8 ; \mathrm{CFI}=0 / 99 ; \mathrm{GFI}=0 / 99 ; p=0 / 001 ; \mathrm{AGFI}=0 / 21 ; \mathrm{RMSEA}=0 / 99$.

attachment style, and DT to be carried out in future.

\section{Acknowledgments}

The author would like to thanks the research section of University of Social welfare and rehabilitation Sciences for funding this study in phase $1 \& 2$.

\section{REFERENCES}

Al tamimi Al madi, A. (1979). Ghorar Al hekam and dorar Al kalam. Beirut: Institute of $\mathrm{Al}$ ailami Press.

Baron, J. (2000). Thinking and deciding (3rd ed.). Cambridge: Cambridge University Press.

Beck, A. T. (2008). The evolution of the cognitive model of depression and its neurobiological correlates. American Journal of Psychiatry, 165, 969-977. http://dx.doi.org/10.1176/appi.ajp.2008.08050721

Beck, A. T. (1975). Cognitive therapy and the emotional disorders. International Universities Press Inc.

Beck, A. T., Epstein, N., \& Harrison, R. (1983). Cognition attitudes and personality dimentions in depression. British Journal of Cognitive Psycholtherapy, 1, 1-16.

Beck, A. T., Rush, A. J., Show, B. F., \& Emery, G. (1979). Cognitive therapy of depression. New York: Guilford Press.

Borooghani, M. (2010). Prediction of forgiveness by deterministic thinking among couples who are volunteers for divorce. Unpuplished M.Sc. Thesis, Tehran: University of Social Welfare and Rehabilitation Sciences.

Burns, D. D. (1989). The feeling good handbook. New York: William Morrow and Co.

Clarck, D., \& Fairburn, M. (1997). Practice of cognitive behavior therapy. London: Oxford Press. http://dx.doi.org/10.1038/37466

Del Missier, F., Ferrante, D., \& Costantini, E. (2007). Focusing effects in predecisional information acquisition. Acta Psychologica, 125, 155-174. http://dx.doi.org/10.1016/j.actpsy.2006.07.005

Faizol Al Islam, A. (1973). Translation and explanation of Nahjo Al balagheh. Tehran: Islamieh Press.

Fleck, L., \& Weiss, K. (2003). The art of fact. Evolutionary Antropology, 12, 168-172. http://dx.doi.org/10.1002/evan.10118

Fincham, F. D., Harold, G. T., \& Gano-Philips, S. (2000). The longitudinal association between attributions and marital satisfaction. Journal of Family Psychology, 14, 267-285. http://dx.doi.org/10.1037/0893-3200.14.2.267

Gertner, J. (2003). The future pursuit of happiness. New York times magazine.

Ghommi, \& Sheikh, A. (1989). Mafatih Al Janan. Tehran: Loghman Press.

Gottman, J. M., Coan, J., Carrère, S., \& Swanson, C. (1998). Predicting marital happiness and stability from newlywed interactions. Journal of Marriage and the Family, 60, 5-22.

http://dx.doi.org/10.2307/353438
Jaafari, \& Mohammad, T. (1981). Scientific cognition in perspective of Quran. Islamic Culture Press.

Klaff, F. (2007). Children of divorce. In F. Shapiro et al. (Eds.), Handbook of EMDR and family therapy processes. Hoboken, NJ: John Wiley and Sons.

Koleini, \& Seghet Al Islam (1980). Osool Al Kaffi. Tehran: Mostafavi Press.

Leahy, T. H. (1987). A history of psychology. Main currents in Psychological thought. McGraw-Hill, NJ: Prentice-Hall International Edition.

Leahy, R. L. (1996). Cognitive therapy: Basic principles and applications. Bergen County, NJ: Northvale.

Maghsoudzade, M. (2010). Prediction of marital satisfaction of shaded sons and spouses by Rate of deterministic thinking and communication skills. Unpuplished M.Sc. Thesis, Tehran: University of Social Welfare and Rehabilitation Sciences.

Momeni, A. (2008). Measuring sensitivity of deterministic thinking scale among happy and unhappy couples. Unpublished M.A. Dissertation in Clinical Psychology, Tehran: Islamic Azad University. Center of Sciences and Researches.

Rah Anjam, H. (2010). Prediction of hope rate by deterministic thinking among in students of Azad Universities of Tehran. Unpuplished M.Sc. Thesis, Tehran: University of Azad (Central branches).

Rottenstreich, Y., \& Hsee, C. K. (2001). Money, kisses, and electric shocks: On the affective psychology of risk. Psychological Science, 12, 185-190. http://dx.doi.org/10.1111/1467-9280.00334

Schkade, D. A., \& Kahneman, D. (1998). Does living in California make people happy? A focusing illusion in judgments of life satisfaction. Psychological Science, 9, 340-346. http://dx.doi.org/10.1111/1467-9280.00066

Shapiro, F. (2007). EMDR and case conceptualization from an adaptive information processing perspective. In F. Shapiro et al. (Eds.), Handbook of EMDR and family therapy processes. Hoboken, NJ: John Wiley and Sons. http://dx.doi.org/10.1002/9781118269985

Smit, Jasper, A. J., Rosenfield, D., \& Mcdonald, R. (2006). Cognitive mechanism of Social anxiety reduction: An examination of specificity and temporality. Journal of Counsulting and Clinical Psychology, 74, 1203-1212.

Sommers-Flanagan, J., \& Sommers-Flanagan, R. (2004). Counseling and psychotherapy. Theories in context and practice. Hoboken, NJ: John Willy.

Teasdale, J. D. (1993). Emotion and two kinds of thinking: Cognitive Therapy and applied Cognitive Sciences. Behavioural Research and Therapy, 31, 339-354. http://dx.doi.org/10.1016/0005-7967(93)90092-9

Teasdale, J. D., \& Bernard, P. J. (1993). Affect, cognition and change. Remodeling depressive thought. Hillsdale, NJ: Erlbaum.

Younesi, J., \& Mirafzal, A. (2007). Development of deterministic thinking questionnaire. Paper Presented to 10th European Congress of Psychology. Prague.

Younesi, J., Younesi, M., \& Asgari, A. (2008). Prediction of rate of marital satisfaction among Tehranian couples by deterministic thinking. 


\section{J. YOUNESI, A. A. MIRAFZAL}

Paper Presented to 28th International Congress of Psychology, Berlin.

Younesi, J. (2005). The major role of cognitive misconceptions "equality in thinking" in psychological disorders. A Journal of Social Sciences And Humanities. The Research Institute of Seminary \& University (HAWZEH VA DANESHGAH), 10, 8-29.

Younesi, J., \& Bahrami, F. (2009). Prediction of rate of marital satisfaction among Tehranian couples by deterministic thinking. Journal of Iranian Psychologists, 14, 34-43.

Warner, R. (2000). The environment of schizophrenia. London \& Philadelphia: Brunner-Routledge.

Weissar, M. E., \& Beck, A. T. (1992). Hopelessness and suicide. International Review of Psychiatry, 4, 177-184.

http://dx.doi.org/10.3109/09540269209066315 